\title{
Commentary
}

\section{A Nutritional Approach to Ameliorate Altered Phospholipid Metabolism in Alzheimer's Disease}

\author{
Tobias Hartmann ${ }^{\mathrm{a}}$, Nick van Wijk ${ }^{\mathrm{b}}$, Richard J. Wurtman ${ }^{\mathrm{c}}$, Marcel G.M. Olde Rikkert ${ }^{\mathrm{d}}$, \\ John W.C. Sijben ${ }^{\mathrm{b}}$, Hilkka Soininen ${ }^{\mathrm{e}}$, Bruno Vellas ${ }^{\mathrm{f}}$ and Philip Scheltens ${ }^{\mathrm{g}, *}$ \\ ${ }^{a}$ Department of Neurodegeneration and Neurobiology, Deutsches Institut für Demenzprävention, Saarland \\ University, Homburg, Germany \\ ${ }^{\mathrm{b}}$ Nutricia Research, Utrecht, The Netherlands \\ ${ }^{\mathrm{c}}$ Department of Brain and Cognitive Sciences, Massachusetts Institute of Technology, Cambridge, Massachusetts, \\ USA \\ ${ }^{\mathrm{d}}$ Radboud Alzheimer Center, Department of Geriatric Medicine, Radboud University Hospital, Nijmegen, \\ The Netherlands \\ ${ }^{\mathrm{e}}$ Department of Neurology, Kuopio University Hospital and University of Eastern Finland, Kuopio, Finland \\ ${ }^{\mathrm{f}}$ Department of Internal and Geriatrics Medicine, Hôpitaux de Toulouse, Toulouse, France

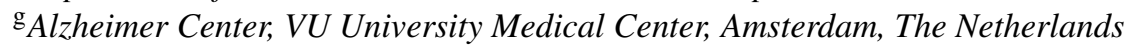

Accepted 27 May 2014

\begin{abstract}
Recently, a biomarker panel of 10 plasma lipids, including 8 phosphatidylcholine species, was identified that could predict phenoconversion from cognitive normal aged adults to amnestic mild cognitive impairment or Alzheimer's disease (AD) within 2-3 years with $>90 \%$ accuracy. The reduced levels of these plasma phospholipids could reflect altered phospholipid metabolism in the brain and periphery. We show that a 24-week nutritional intervention in drug-naive patients with very mild to mild AD significantly increased 5 of the 7 measured biomarker phosphatidylcholine species. By providing nutrients which normally rate-limit phospholipid synthesis, this nutritional intervention could be useful in asymptomatic subjects with a plasma lipid biomarker profile prognostic of AD.
\end{abstract}

Keywords: Alzheimer's disease, membranes, nutritional intervention, phosphatidylcholine, plasma phospholipids, prognostic biomarkers, synaptic dysfunction

\section{INTRODUCTION}

Mapstone et al. [1] recently identified and validated a set of 10 plasma lipids that could predict phenocon-

\footnotetext{
${ }^{*}$ Correspondence to: Philip Scheltens, MD, Department of Neurology and Alzheimer Center, Neuroscience Campus Amsterdam, VU University Medical Center, Amsterdam, The Netherlands. Tel.: +31 20 4440816; Fax: +31 20 4440715; E-mail: p.scheltens@ vumc.nl.
}

version to either amnestic mild cognitive impairment (aMCI) or Alzheimer's disease (AD). This 10 biomarker panel encompassed 8 phosphatidylcholine (PC) and 2 other molecules. Levels of these compounds were reduced in the plasma of the converter subjects (before conversion) compared to the non-convertors (normal control group). These metabolites remained low after conversion to aMCI/AD and were similar to the levels in the group with aMCI/AD at inclusion. 
Table 1

Plasma concentration of specific phosphatidylcholine (PC) species

\begin{tabular}{|c|c|c|c|c|c|}
\hline & \multicolumn{2}{|c|}{$\begin{array}{l}\text { Control product } \\
(n=49)\end{array}$} & \multicolumn{2}{|c|}{$\begin{array}{l}\text { Investigational product } \\
(n=47)\end{array}$} & \multirow{2}{*}{$\begin{array}{c}\text { ANCOVA (control versus } \\
\text { investigational product) } \\
p \text { value }\end{array}$} \\
\hline & Baseline & 24-week & Baseline & 24-week & \\
\hline $\mathrm{PC}$ aa $\mathrm{C} 36: 6, \mu \mathrm{M}$ & $1.45 \pm 0.77$ & $1.22 \pm 0.69$ & $1.62 \pm 0.71$ & $2.28 \pm 0.77$ & $<0.0001$ \\
\hline $\mathrm{PC}$ aa $\mathrm{C} 38: 0, \mu \mathrm{M}$ & $5.12 \pm 2.20$ & $3.78 \pm 1.73$ & $4.89 \pm 1.93$ & $6.32 \pm 1.83$ & $<0.0001$ \\
\hline $\mathrm{PC}$ aa $\mathrm{C} 38: 6, \mu \mathrm{M}$ & $63.91 \pm 24.94$ & $70.53 \pm 31.52$ & $70.71 \pm 23.97$ & $151.85 \pm 39.13$ & $<0.0001$ \\
\hline $\mathrm{PC}$ aa $\mathrm{C} 40: 2, \mu \mathrm{M}$ & $2.45 \pm 1.68$ & $1.37 \pm 1.21$ & $2.55 \pm 1.42$ & $1.60 \pm 1.09$ & 0.3439 \\
\hline $\mathrm{PC}$ aa $\mathrm{C} 40: 6, \mu \mathrm{M}$ & $23.05 \pm 9.61$ & $25.66 \pm 11.84$ & $26.84 \pm 9.57$ & $60.42 \pm 17.94$ & $<0.0001$ \\
\hline $\mathrm{PC}$ ae $\mathrm{C} 40: 6, \mu \mathrm{M}$ & $4.37 \pm 1.43$ & $4.48 \pm 1.64$ & $4.67 \pm 1.37$ & $7.94 \pm 2.14$ & $<0.0001$ \\
\hline lysoPC a C18:2, $\mu \mathrm{M}$ & $22.42 \pm 8.33$ & $23.16 \pm 11.65$ & $21.40 \pm 8.20$ & $20.29 \pm 7.22$ & 0.1952 \\
\hline
\end{tabular}

Quantitative data are presented as mean \pm standard deviation. PC aa C40:1, Propionyl acylcarnitine (C3) and C16:1-OH were reported by Mapstone et al. [1], but were not measured in the current analysis. PC aa, diacyl form; PC ae, acyl-alkyl form.

As the authors indicated, the identified lipids have essential roles in the integrity and functionality of neuronal membranes, including synaptic membranes. The synapse loss and dysfunction characteristic of $\mathrm{AD}$ have been linked to the degeneration of neuronal membranes and increased breakdown of membrane phospholipids [2-4]. Mapstone et al. postulated that the observed changes in plasma phospholipid levels reflect the breakdown of neuronal membranes among individuals who convert within 3 years to aMCI/AD, and mark the preclinical transition to subtle cognitive changes [1]. Several other recent studies have demonstrated reduced plasma levels of several PC species in $\mathrm{AD}$ and MCI subjects [5-7], including some of the PCs identified by Mapstone et al., indicating altered phospholipid metabolism in AD. Whether the changes in plasma PCs concentration directly originate from disturbed PC metabolism in the brain, or are caused by disturbed PC metabolism in peripheral organs (e.g., liver) remains to be elucidated.

\section{OUR FINDINGS}

We previously tested, in drug-naive patients with very mild to mild $\mathrm{AD}$ [8], the nutritional intervention Souvenaid ${ }^{\circledR}$ (125 mL, taken once daily) containing the specific nutrient combination Fortasyn ${ }^{\circledR}$ Connect in a 24-week, randomized, controlled, double-blind, parallel-group, multi-country trial. This nutrient combination was designed to enhance the formation and function of synaptic membranes and comprises uridine monophosphate (UMP, $625 \mathrm{mg}$ ), the long-chain omega-3 polyunsaturated fatty acids docosahexaenoic acid (DHA, $1200 \mathrm{mg}$ ) and eicosapentaenoic acid (EPA, $300 \mathrm{mg}$ ), choline (400 mg), phospholipids (106 mg), folic acid $(400 \mu \mathrm{g})$, vitamin B12 (3 $\mu \mathrm{g})$, vitamin B6 $(1 \mathrm{mg})$, vitamin C (80 mg), vitamin E (40 mg), and selenium $(60 \mu \mathrm{g})$ [8]. In the present study, some baseline and 24-week plasma samples, chosen at random, of subjects taking either the investigational product $(n=47)$ or a control product $(n=49)$ were analyzed for lipid profiles at the Kansas Lipidomics Research Center using electrospray ionization tandem mass spectrometry (ESI-MS/MS). Phospholipid concentrations were compared between intervention groups at 24 weeks whilst controlling for baseline values by using an analysis of covariance (ANCOVA) model. Five of the 7 measured PCs reported by Mapstone et al. [1], were significantly increased following the 24-week treatment with the nutrient combination (see Table 1). These results indicate that a biomarker profile reflecting disturbed phospholipid metabolism and perhaps indicative of early neurodegeneration can be modified in $\mathrm{AD}$ by providing nutrients which ratelimit phospholipid biosynthesis. These nutrients are substrates in the Kennedy pathway which synthesizes the phospholipids present in synaptic membranes [9, 10]. Enhancing the availability of these nutrients could thus increase synapse number and memory function in $\mathrm{AD}$ [11]. Previous observations from the same study indicate that the current changes in plasma PCs levels are accompanied by improved memory performance $[8,12]$ and preserved functional connectivity and brain network organization, as assessed by EEG analyses [13] in patients with mild AD, supporting the hypothesis that this nutritional intervention ameliorates synaptic dysfunction. Thus, these observations indicate that the changes in peripheral phospholipids may be indicative for the changes induced in the brain, i.e., increased synaptic membrane synthesis. It is reasonable to expect that the current nutritional intervention induces similar changes in the peripheral phospholipid levels in preclinical AD subjects, while the implications for disease risk modification are uncertain and need further investigation. In conclusion, 
our findings suggest that a nutritional intervention that raises levels of nutrients normally rate-limiting in phospholipid synthesis may also be useful in asymptomatic subjects with plasma lipid biomarker profiles predictive for phenoconversion to aMCI/AD.

\section{DISCLOSURE STATEMENT}

Authors' disclosures available online (http://www.jalz.com/disclosures/view.php?id=2364).

\section{REFERENCES}

[1] Mapstone M, Cheema AK, Fiandaca MS, Zhong X, Mhyre TR, Macarthur LH, Hall WJ, Fisher SG, Peterson DR, Haley JM, Nazar MD, Rich SA, Berlau DJ, Peltz CB, Tan MT, Kawas CH, Federoff HJ (2014) Plasma phospholipids identify antecedent memory impairment in older adults. Nat Med 20, 415-418.

[2] Prasad MR, Lovell MA, Yatin M, Dhillon H, Markesbery WR (1998) Regional membrane phospholipid alterations in Alzheimer's disease. Neurochem Res 23, 81-88.

[3] Nitsch RM, Blusztajn JK, Pittas AG, Slack BE, Growdon JH, Wurtman RJ (1992) Evidence for a membrane defect in Alzheimer disease brain. Proc Natl Acad Sci U S A 89, 1671-1675.

[4] Pettegrew JW, Panchalingam K, Hamilton RL, McClure RJ (2001) Brain membrane phospholipid alterations in Alzheimer's disease. Neurochem Res 26, 771-782.

[5] Oresic M, Hyotylainen T, Herukka SK, Sysi-Aho M, Mattila I, Seppanan-Laakso T, Julkunen V, Gopalacharyulu PV, Hallikainen M, Koikkalainen J, Kivipelto M, Helisalmi S, Lotjonen J, Soininen H (2011) Metabolome in progression to Alzheimer's disease. Transl Psychiatry 1, e57.
[6] Whiley L, Sen A, Heaton J, Proitsi P, Garcia-Gomez D, Leung R, Smith N, Thambisetty M, Kloszewska I, Mecocci P, Soininen H, Tsolaki M, Vellas B, Lovestone S, Legido-Quigley C, AddNeuroMed C (2014) Evidence of altered phosphatidylcholine metabolism in Alzheimer's disease. Neurobiol Aging 35, 271-278.

[7] Gonzalez-Dominguez R, Garcia-Barrera T, Gomez-Ariza JL (2014) Combination of metabolomic and phospholipidprofiling approaches for the study of Alzheimer's disease. J Proteomics. doi: 10.1016/j.jprot.2014.01.014

[8] Scheltens P, Twisk JW, Blesa R, Scarpini E, von Arnim CA, Bongers A, Harrison J, Swinkels SH, Stam CJ, de Waal H, Wurtman RJ, Wieggers RL, Vellas B, Kamphuis PJ (2012) Efficacy of souvenaid in mild Alzheimer's disease: Results from a randomized, controlled trial. J Alzheimers Dis 31, 225236.

[9] Sakamoto T, Cansev M, Wurtman RJ (2007) Oral supplementation with docosahexaenoic acid and uridine- $5^{\prime}$ monophosphate increases dendritic spine density in adult gerbil hippocampus. Brain Res 1182, 50-59.

[10] Wurtman RJ, Ulus IH, Cansev M, Watkins CJ, Wang L, Marzloff G (2006) Synaptic proteins and phospholipids are increased in gerbil brain by administering uridine plus docosahexaenoic acid orally. Brain Res 1088, 83-92.

[11] van Wijk N, Broersen LM, de Wilde MC, Hageman RJ, Groenendijk M, Sijben JW, Kamphuis PJ (2014) Targeting synaptic dysfunction in Alzheimer's disease by administering a specific nutrient combination. J Alzheimers Dis 38, 459-479.

[12] Scheltens P, Kamphuis PJ, Verhey FR, Olde Rikkert MG, Wurtman RJ, Wilkinson D, Twisk JW, Kurz A (2010) Efficacy of a medical food in mild Alzheimer's disease: A randomized, controlled trial. Alzheimers Dement 6, 1-10 e11.

[13] de Waal H, Stam CJ, Lansbergen MM, Wieggers RL, Kamphuis PJ, Scheltens P, Maestu F, van Straaten EC (2014) The effect of souvenaid on functional brain network organisation in patients with mild Alzheimer's disease: A randomised controlled study. PLoS One 9, e86558. 